\title{
Determination of Entrapment Victim Extrication Forces with and without Use of a Grain Rescue Tube
}

\author{
M. J. Roberts, W. E. Field, D. E. Maier, R. L. Stroshine
}

\begin{abstract}
The forces required to extricate a test mannequin from a grain mass when buried at different depths with and without a grain restraint system were determined. When there was no grain restraint system in place, the vertical force required to pull the mannequin from the grain when it was buried waist deep and to the underarms was 1259 and $1766 N\left(283\right.$ and $\left.397 l b_{f}\right)$, respectively. It increased to $1584 N\left(356 l b_{f}\right)(+26 \%)$ and $2153 \mathrm{~N}\left(484 l b_{f}\right)(+22 \%)$, respectively, with the restraint in place due to the changes in grain properties brought about by the insertion of the rescue tube. It was concluded that the use of a grain restraint during extrication of a victim does not reduce the forces required and that forcefully pulling an entrapped victim, especially with mechanical assistance, with or without a grain restraint system could result in severe injuries and possible death due to the forces exerted on the victim. The authors recommend that these findings be incorporated into current grain extrication training for emergency first responders.
\end{abstract}

Keywords. Grain bin rescue, Grain entrapment, Grain rescue tubes.

$\mathrm{T}$ There are tremendous forces acting on a person who is entrapped in a grain mass that prevent him from self-extrication or even from being rescued by means of a vertical pull. In addition to those forces, other reasons why vertical-pull extrication is often impractical include: the lack of adequate overhead tie-off and anchor points for rope rigging, the lack of access to mechanical-assist lifting devices, and the known detrimental effects on the human body resulting from the application of the pulling forces needed for extrication. There have been documented cases in which victims of partial entrapment in grain were fatally or seriously injured when attempts were made to extricate them by physically pulling on their bodies (Roberts et al., 2012). These injuries have included dislocated joints, internal injuries, and separated spine. No data, however, were found that specified the acceptable forces that can be applied to the body without causing injury when it is being freed from a grain mass.

The grain rescue tube was developed as a means of providing temporary protection for a person entrapped in grain and to allow grain to be removed from around the victim

Submitted for review in February 2013 as manuscript number JASH 10150; approved for publication by the Ergonomics, Safety, \& Health Community of ASABE in January 2015.

The authors are Matthew J. Roberts, Co-Owner/Operator, J\&M Roberts LLC, Syracuse, Indiana; William E. Field, ASABE Fellow, Professor, Department of Agricultural and Biological Engineering, Purdue University, West Lafayette, Indiana; Dirk E. Maier, ASABE Member, Professor and Head, Department of Grain Science and Industry, Kansas State University, Manhattan, Kansas; Richard L. Stroshine, ASABE Member, Professor, Department of Agricultural and Biological Engineering, Purdue University, West Lafayette, Indiana. Corresponding author: William Field, ABE Building, 225 South University St., West Lafayette, IN 47907-2093; phone: 765-494-1191; email: field@purdue.edu.

Journal of Agricultural Safety and Health

21(2): $71-83 \quad$ C 2015 ASABE ISSN 1074-7583 DOI 10.13031/jash.21.10150 
within the tube so that the person can be safely extricated. Although not documented, rescue professionals generally believe that the rescue tube not only protects the victim from deeper engulfment but also reduces the forces on his body. Based on documentation of successful rescues and their use in rescue training, under controlled conditions, when the grain from within the tube is partially removed, the tubes are effective (Roberts et al., 2012). However, no tests have been carried out to determine whether the victim could be more easily pulled from the grain mass with the tube in place. Thus, an important question is whether rescue tubes alleviate enough pressure from around an entrapped victim to facilitate safe vertical-pull extrication. The purpose of this study was to evaluate entrapment victim extrication forces with and without the use of a grain rescue tube.

\section{Literature Review}

Following is a summary of articles found in the literature that provide information on the forces required to extricate a person trapped in grain.

\section{Pull Forces in Grain Entrapment Rescue}

Two studies were identified that determined the amount of effort and/or force needed to extricate an entrapped individual or object. The first was conducted in Germany by Schmechta and Matz (1971). They measured the depth to which a $75 \mathrm{~kg}$ (165 lb) live human male sank when standing in barley and rape seed grain masses. In barley, the subject sank until the grain was $10 \mathrm{~cm}$ (4 in.) below the knees; in rape seed, the depth to which he sank was $10 \mathrm{~cm}$ (4 in.) above the knees. In both instances, the individual was able to extricate himself from the grain.

Schmechta and Matz (1971) subsequently performed tests in flowing barley using an overhead tie-off point, safety rope, and harness to secure their subject. In the first set of tests, the subject was allowed to sink to his knees; at that level, self-extrication was difficult yet possible. Next, the subject was allowed to sink to his waist, at which point selfextrication was not possible. However, extrication was accomplished with the aid of another person. In the third set of tests, the subject was buried to his shoulders. At that depth, not only was he helpless but also the weight of the grain made breathing difficult. (We do not condone this type of test because of the potential risk to the individual being buried. In fact, this type of study most likely could not be performed today due to limitations placed on research by institutional review boards.) Furthermore, in attempting to remove the subject from the grain, unexpected problems were encountered. First, the rope and harness were damaged and rendered useless. Another person subsequently entered the test structure to help extricate the subject, but to no avail. Finally, the barley had to be shoveled away from around the subject before extrication was possible. Findings suggested that significant injury to the test subject would have occurred if a vertical force had been applied in an attempt to extricate him.

In the second study, Schwab (1982), working at the University of Kentucky, attempted to quantify the force needed to extricate an entrapped victim under three different grain

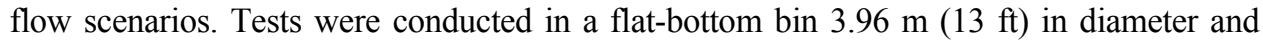
$20.42 \mathrm{~m}(67 \mathrm{ft})$ in height, with both corn and wheat, using a $75 \mathrm{~kg}(165 \mathrm{lb})$ adult mannequin, a $24 \mathrm{~kg}(53 \mathrm{lb})$ child mannequin, and a $73 \mathrm{~kg}(161 \mathrm{lb})$ peg. The study used three types of grain flow scenarios: static (grain that was not moving), flowing (grain that was being drawn out the bottom of the bin), and transitional flow. Schwab described transitional flow as flow that is changing from fully developed plug flow to fully developed enveloping flow. 
Schwab et al. (1985) extricated the simulated victims using a winch and placed a load cell between the victim and the winch cable. The adult and child mannequins were placed in a harness that was attached to the cable coming from the load cell. For the experiment involving the peg, the point of attachment was an eyelet at the top of the peg. In carrying out the tests, the simulated victims were submerged to a depth of $1.4 \mathrm{~m}(4.6 \mathrm{ft})$ and then winched up and out at a constant rate of $0.402 \mathrm{~m} \mathrm{~min}^{-1}\left(1.32 \mathrm{ft} \mathrm{min}^{-1}\right)$. Schwab et al. (1985) established ten different points of reference (i.e., the depth of the grain relative to the simulated victim) at which the force being applied during the pulling process was measured. The average magnitude of pull (expressed in $\mathrm{N}$ ) was recorded at each of the ten points for the adult mannequin and the peg in corn, for the child mannequin in corn, and for the peg in wheat. The averages of the static and flowing tests were calculated (Schwab et al., 1985).

Schwab's study was the only one found that included the vertical force applied to an adult mannequin being pulled from corn at a specific depth. No study was found that documented the use of a grain retaining wall or grain rescue tube and the amount of pull exerted on the entrapped victim during extrication when using such a device, which was the objective of this investigation.

\section{Pull Forces on the Human Body}

No studies were found in the literature that evaluated the amount of pull the human body can tolerate. We assume that a wide range of forces would be required to injure the victim and that the force would depend on the person's size, shape, bone density, and muscularity. Other factors could include the presence of artificial joints or prior musculoskeletal injuries. One source that provides some insight into the maximum allowable pull that the human body can withstand is OSHA Standard 1926.502, titled "Fall Protection Systems Criteria and Practices," which gives the requirements for fall arrest systems (OSHA, 2008). The specific section relevant to this study was 1926.502(d)(16), which mandates that: "Personal fall arrest systems, when stopping a fall, shall (i) limit maximum arresting force on an employee to 900 pounds $(4 \mathrm{kN})$ when used with a body belt and (ii) limit maximum arresting force on an employee to 1,800 pounds $(8 \mathrm{kN})$ when used with a body harness." The standard does not reference how these acceptable forces were determined.

Using this OSHA standard requirement as a reference point, it was assumed for the purpose of this study that the maximum force an average adult body may tolerate is $4 \mathrm{kN}$ $\left(900 \mathrm{lb}_{\mathrm{f}}\right)$ when wearing a body belt, and the maximum allowable force increases to $8 \mathrm{kN}$ $\left(1800 \mathrm{lb}_{\mathrm{f}}\right)$ when wearing a full-body harness. However, neither of these limitations directly applies to pulling forces applied to a victim partially buried in free-flowing material of any type.

\section{Methodology}

Tests were conducted in a $2.74 \mathrm{~m}(9 \mathrm{ft})$ diameter hopper-bottom bin located at the Post-Harvest Education and Research Center (PHERC) at Purdue University's Agronomy Center for Research and Education (fig. 1). An overhead tie-off point was constructed for the purpose of carrying out vertical-pull extrication, with a load cell (S-Beam, Omega Engineering, Stamford, Conn.) rated for $22 \mathrm{kN}\left(5000 \mathrm{lb}_{\mathrm{f}}\right)$ attached to the tie-off point. The load cell was connected to a winch rated for $1814 \mathrm{~kg}(4500 \mathrm{lb})$, which was used to extricate the simulated victim. The simulated victim was a life-size, $74.84 \mathrm{~kg}(165 \mathrm{lb})$, 
$1.83 \mathrm{~m}(6 \mathrm{ft})$ tall rescue mannequin dressed in firefighter bib overalls and jacket. A fullbody, ANSI-rated safety harness with a back-mounted D-ring was placed on the mannequin and served as the point of attachment for the winch cable (fig. 2).

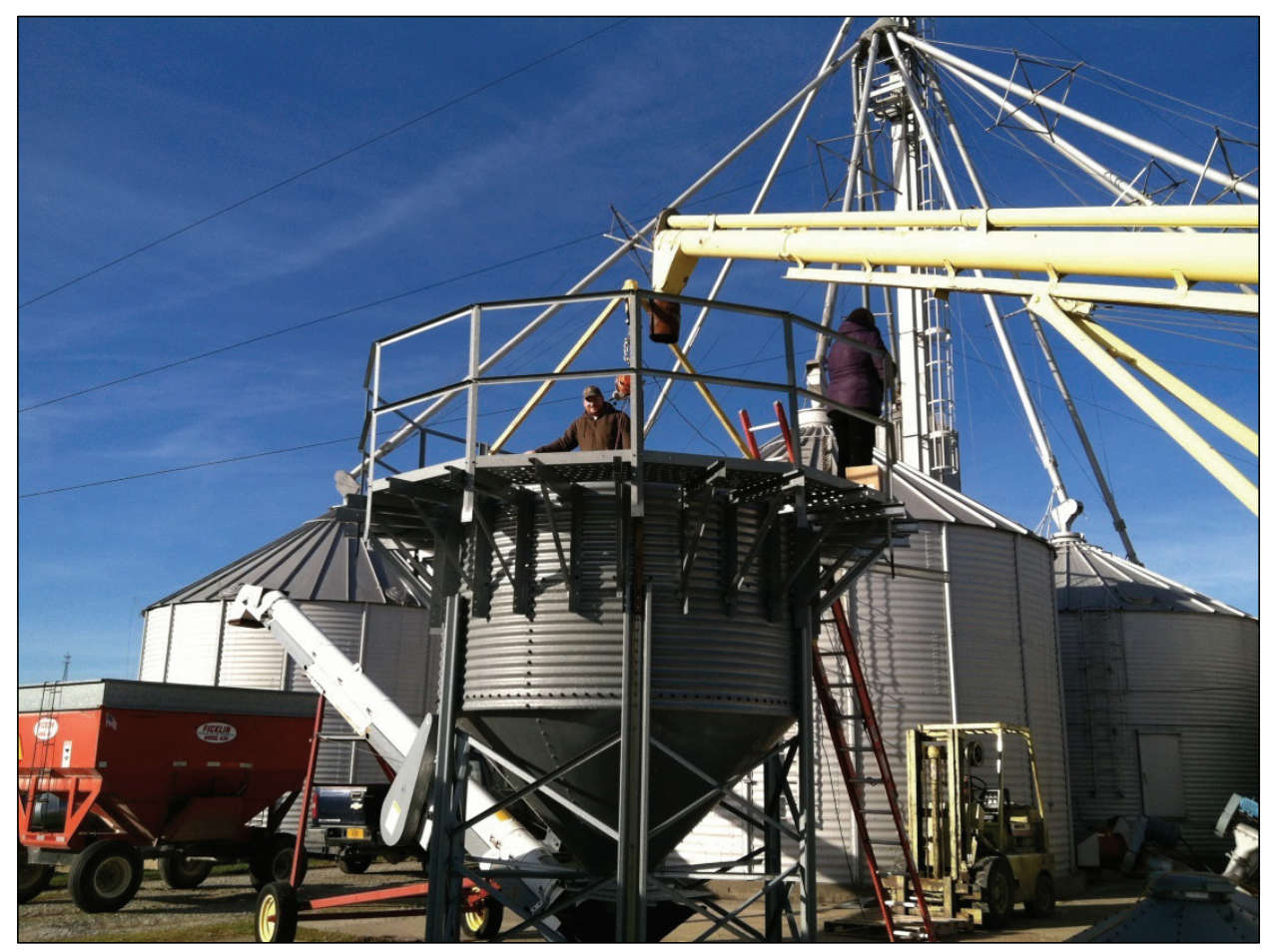

Figure 1. Photo of test facility used to measure vertical pull force.

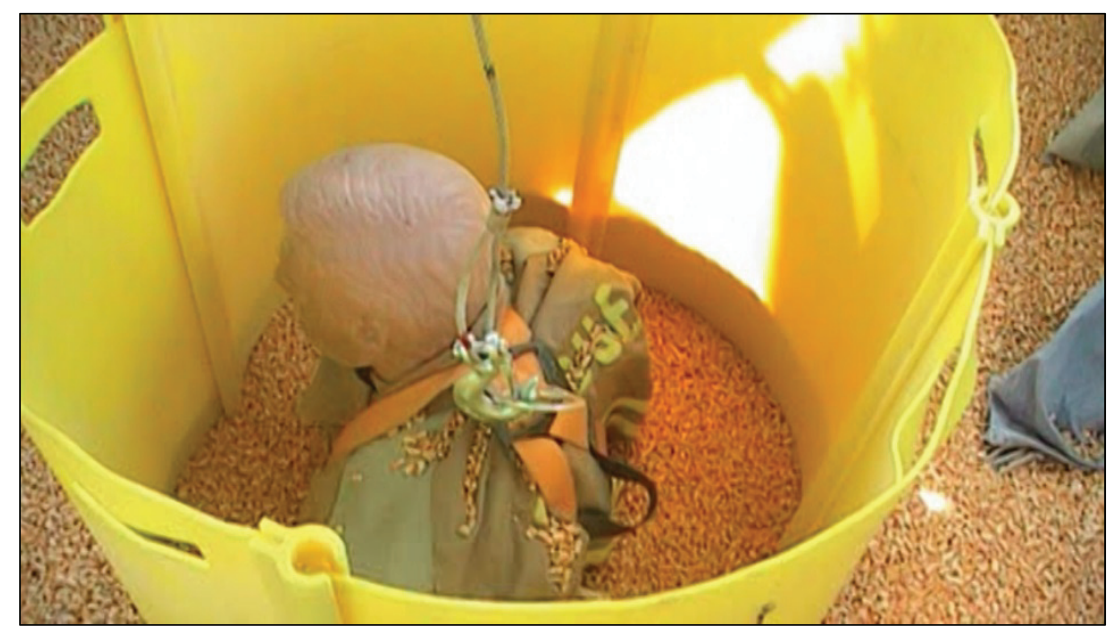

Figure 2. Grain rescue tube in place around simulated victim. 
The simulated victim was entrapped by removing grain from the bottom outlet of the hopper bin. As the grain began to move as a result of gravity flow, the victim was drawn into the grain mass. The tests were conducted by first entrapping the mannequin and then winching it out of the grain while collecting the load cell readings of the forces on the cable. The extraction forces required with and without the rescue tube were quantified using vertical pull tests conducted at two mannequin entrapment depths (to the waist and to the underarms) with and without the use of a grain rescue tube.

The rescue tube used for these tests is commercially available from Liberty Rescue Systems and consists of four panels of UHMW plastic that interlock to form a tube that can be inserted into the grain around the victim. Each panel is approximately $1.54 \mathrm{~m}$ $(5 \mathrm{ft})$ in length. Use of this product does not imply endorsement of the product by the authors or Purdue University.

\section{Test Procedures}

Six different tests were conducted, all in yellow corn dried to a moisture content of $14 \%$ wet basis. The bulk density of the corn was measured as $730 \mathrm{~kg} \mathrm{~m}^{-3}\left(56.7 \mathrm{lb} \mathrm{bu}^{-1}\right)$. The hopper-bottom tank was two rings deep with a $45^{\circ}$ cone and had a capacity of $3 \mathrm{~m}^{3}$ (400 bu). The tank was filled using a $20 \mathrm{~cm}$ ( 8 in.) portable inclined power takeoff operated screw conveyor. Grain was removed from the base of the tank with an electric motor driven belt conveyor. A total of six tests were performed by sinking the mannequin into the grain mass to the two predetermined depths (waist and underarms); three tests were conducted at each entrapment depth.

In the first series of tests, the mannequin was entrapped to the waist and underarm depths and then a $113 \mathrm{~kg}(250 \mathrm{lb})$ man walked around the entrapped mannequin three times. The walk-around tests were meant to simulate likely real-life rescue scenarios in which rescuers enter a grain storage structure in order to make contact with and stabilize the victim. Based on prior observations at grain rescue training sessions, it is known that walking around an entrapped individual increases the amount of pressure exerted on him (Roberts et al., 2011). After the walk-around was completed, the entrapment simulation bin was cleared of workers and the mannequin was pulled from the grain mass with the overhead winch. The peak pull force displayed by the load cell was recorded with a video camera. The speed of pull was calculated to be 6 to $8.5 \mathrm{~m} \mathrm{~min}^{-1}$ (20 to $\left.28 \mathrm{ft} \mathrm{min}^{-1}\right)$.

In the second series of tests, the mannequin was again entrapped to the two predetermined depths, and then the grain rescue tube was inserted around the mannequin. When

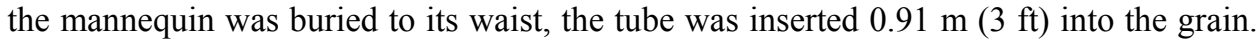
At this depth, the bottom of the tube was even with the mannequin's feet. When the mannequin was buried to its underarms, the tube was inserted about $1.22 \mathrm{~m}(4 \mathrm{ft})$ deep, so that the top of the tube was level with the top of the mannequin's head.

In the tests that used the grain rescue tube (i.e., the second and third series), the tube was first assembled outside of the bin in which the entrapment was simulated. After the mannequin had been entrapped to the predetermined depth, three people entered the bin to insert the tube around the mannequin. No special apparatus was placed on or in the grain in order to prevent or reduce compaction of the grain, as there would typically be no such device in a real-world rescue scenario. Several rescue incidents have been documented in which a working surface was formed around the rescue tube to provide better footing for the rescuers (Roberts et al., 2012). These platforms were fabricated from plywood, flexible matting, 
and soda bottle crates. It was not noted whether these surfaces reduced compaction.

The tube was inserted by first manually pressing each individual panel down into the grain. Using a pipe provided with the tube, the panels could only be inserted approximately 0.46 to $0.76 \mathrm{~m}$ (1.5 to $2.5 \mathrm{ft}$ ) deep (fig. 3). A panel driver (fig. 4), also provided with the tube, was then used to drive the panels down to the necessary depth for testing. The driver consisted of a slide hammer that fits over the top edge of each panel, allowing the panels to be driven uniformly into the grain. The authors have also conducted tests on the effort required to insert grain rescue tube panels into grain of differing moisture contents (see Roberts et al., 2012). After the tube was in place around the mannequin and the entrapment simulation bin was cleared, the mannequin was pulled from the grain mass with the overhead winch, and the peak pull force displayed by the load cell was once again recorded with a video camera.

For the third series of tests, the mannequin was entrapped to the same predetermined

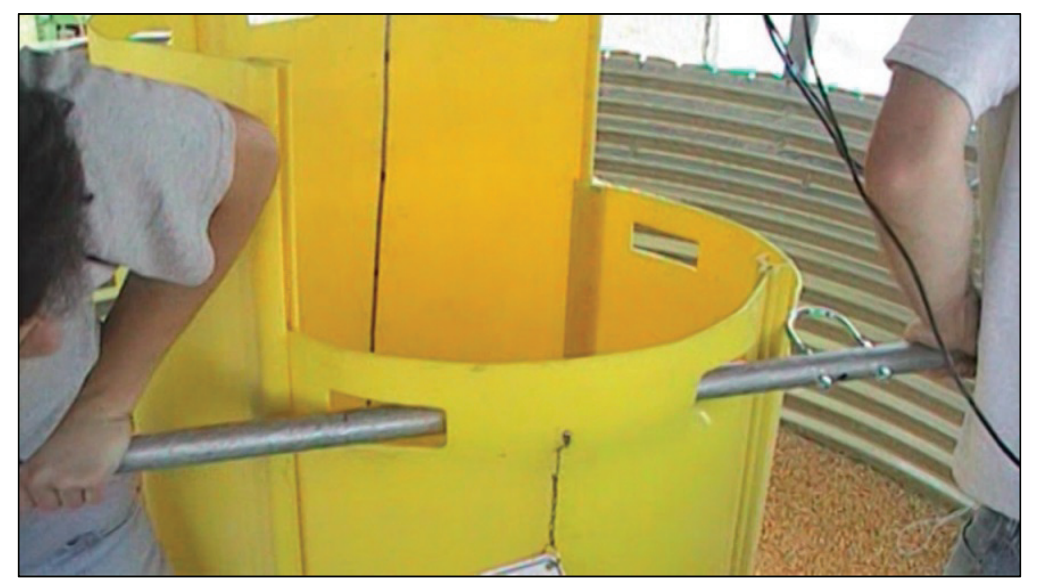

Figure 3. Grain rescue tube panels being manually inserted into the grain mass with a pipe running through the panel's hand-holds.

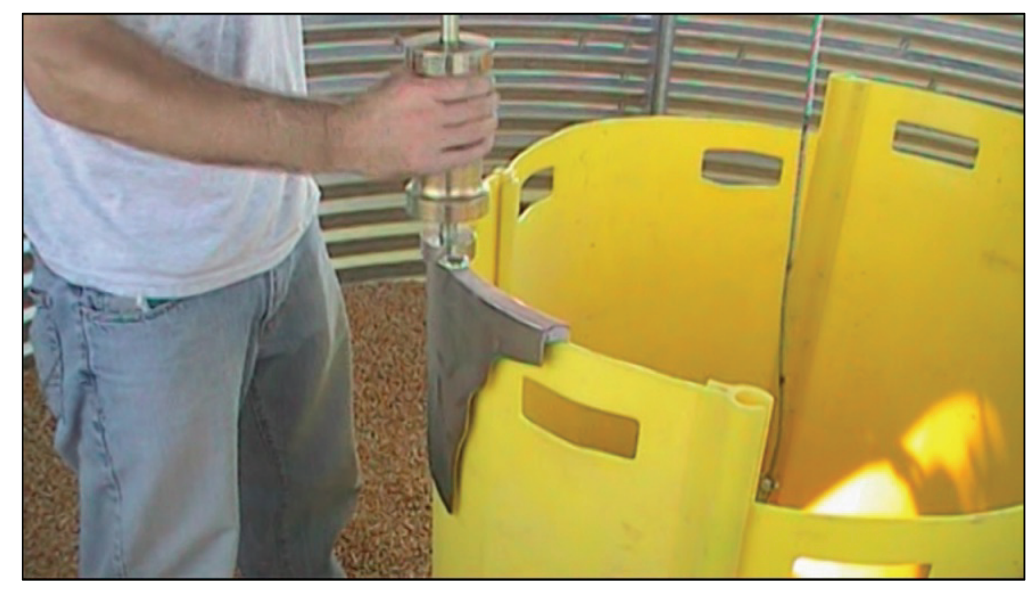

Figure 4. Grain rescue tube panels being driven further into the grain mass with the panel driver. 
depths as in the previous two tests, and the grain rescue tube was inserted around the mannequin using the same procedure as described for the second series. However, this time, grain was extracted from within the tube using a wet/dry shop vacuum. When the mannequin was buried to its waist, the grain was removed until the mannequin's knees were exposed. When the mannequin was buried to its underarms, the grain was removed until the mannequin's waist was exposed.

In each scenario, after the grain had been extracted from around the mannequin, the entrapment simulation bin was cleared and the mannequin was pulled from the grain mass using the overhead winch, with the load cell forces recorded by a video camera.

The following is a summary of the six test extrication scenarios described above:

1. Victim entrapped to waist with walk-around only (no rescue tube).

2. Victim entrapped to waist with rescue tube inserted.

3. Victim entrapped to waist with tube inserted and grain removed to knees.

4. Victim entrapped to underarms with walk-around only (no rescue tube).

5. Victim entrapped to underarms with rescue tube inserted.

6 . Victim entrapped to underarms with tube inserted and grain removed to waist.

Each of the six scenarios was repeated for a minimum of three replications. When the data varied between replications by more than $444.82 \mathrm{~N}\left(100 \mathrm{lb}_{\mathrm{f}}\right)$ from previous tests for a given scenario, a fourth replication was conducted to obtain another data point. No more than four trials had to be conducted for a given scenario.

\section{Results}

Before the extraction tests were conducted, it was hypothesized that inserting a grain rescue tube around a victim who was entrapped in grain would separate the victim from the rest of the grain mass, thereby reducing the pressure acting on him. This assumption seemed to be supported by observations made during simulated rescues by professional rescue training personnel and information provided by the manufacturers of commercially available rescue tubes. It was thought that, by inserting the tube around the victim (without removing grain from inside the tube), the pressure would be reduced sufficiently so that vertical-pull extrication would be a viable rescue option. The results reported here negate that hypothesis.

The tests were designed to measure the force needed to pull the mannequin up and out of a grain mass. In each of the trials, the maximum pull was exerted on the mannequin just as it began to move up through the grain mass. Beyond that point, the amount of pull continued to decrease as more of the mannequin emerged from the grain mass until it decreased to its dead weight once clearing the grain surface.

Figure 5 shows the average pull force for each test scenario. The variation in the pull force across all trials within each series of tests ranged from as little as $9 \%$ increase in the case of entrapment to the waist with the walk-around and without the rescue tube to as much as $37 \%$ increase for entrapment to the underarms with the grain inside the tube removed to waist level. The chart clearly shows that the pull force increased when the tube was inserted around the victim (an unexpected result) and then decreased when a portion of the grain within the tube was removed (a predicted outcome). 


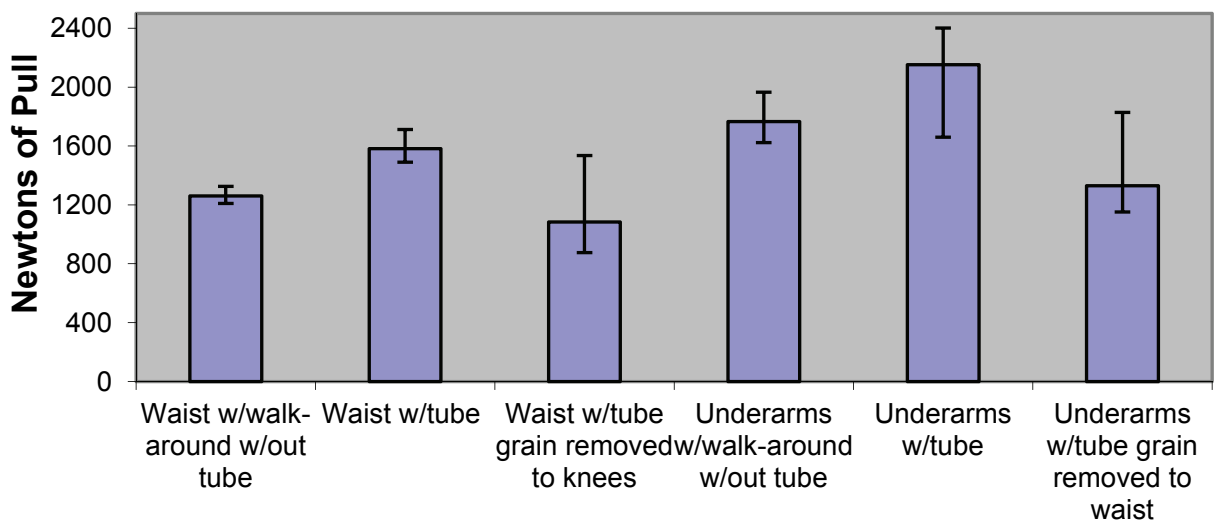

Test Scenario

Figure 5. Average pull force required to extricate a mannequin in various entrapment scenarios (error bars indicate minimum and maximum pull forces documented).

The magnitudes of the pull force increase or decrease between the different test scenarios were as follows:

- When the mannequin was entrapped to its waist, the average force needed for vertical extrication increased by $26 \%$ when the tube was inserted versus when there was no tube, i.e., 1259 vs. $1584 \mathrm{~N}$ ( 283 vs. $356 \mathrm{lb}_{\mathrm{f}}$ ).

- When the mannequin was entrapped to its underarms, the force needed for vertical extrication increased by $22 \%$ when the tube was inserted versus when there was no tube, i.e., 1766 vs. $2153 \mathrm{~N}$ (397 vs. $484 \mathrm{lb}_{\mathrm{f}}$ ).

- When the mannequin was entrapped to its waist with the tube inserted, the average force needed for extrication decreased by $31 \%$ when grain within the tube was removed to knee level versus when no grain was removed from within the tube, i.e., 1584 vs. $1085 \mathrm{~N}$ (356 vs. $244 \mathrm{lb}_{\mathrm{f}}$ ). This test resulted in the least force required to extricate the mannequin.

- When the mannequin was entrapped to its underarms with the tube inserted and grain within the tube removed to the waist, the force needed for extrication decreased by $38 \%$ versus when no grain was removed from within the tube, i.e., 2153 vs. $1330 \mathrm{~N}$ (484 vs. $\left.299 \mathrm{lb}_{\mathrm{f}}\right)$.

To determine the volume of the mannequin, circumference measurements were taken at $15 \mathrm{~cm}$ (6 in.) intervals, starting at the underarms and continuing down toward the feet. The volume was calculated by assuming that each segment was a cylinder with the same circumference and a height of $15 \mathrm{~cm}(6 \mathrm{in}$.) and then summing the volumes of all the cylinders. Two additional measurements were taken at the waist and at $8 \mathrm{~cm}(3 \mathrm{in}$.) below the waist for the purpose of quantifying the mannequin's volume when buried to the specified depth. From these circumference measurements, the volumes of the mannequin between the underarms and $15 \mathrm{~cm}$ ( 6 in.) below the underarms and between the waist and $8 \mathrm{~cm}\left(3 \mathrm{in}\right.$.) below the waist were calculated to be $0.015 \mathrm{~m}^{3}\left(0.53 \mathrm{ft}^{3}\right)$ and $0.009 \mathrm{~m}^{3}$ $\left(0.32 \mathrm{ft}^{3}\right)$, respectively. The volume of the tube prior to insertion was approximately $1 \mathrm{~m}^{3}$ 
Table 1. Comparison of test scenarios in which the mannequin was buried to its waist and underarms, the associated average pull force recorded for each scenario with and without the tube, and the calculated increase in bulk density due to tube insertion.

\begin{tabular}{|c|c|c|c|c|}
\hline \multirow[b]{2}{*}{ Scenario } & \multicolumn{2}{|c|}{ Average Amount of Pull Force, N ( $\left(\mathrm{lb}_{\mathrm{f}}\right)$} & \multirow{2}{*}{$\begin{array}{c}\text { Pull Force } \\
\text { Increase due to } \\
\text { Tube Insertion }\end{array}$} & \multirow{2}{*}{$\begin{array}{l}\text { Bulk Density } \\
\text { Increase due to } \\
\text { Consolidation }\end{array}$} \\
\hline & Without Tube & With Tube & & \\
\hline Waist & $1259(283)$ & $1584(356)$ & $26 \%$ & $9 \%$ \\
\hline Underarms & $1766(397)$ & $2153(484)$ & $22 \%$ & $16 \%$ \\
\hline
\end{tabular}

$\left(35.36 \mathrm{ft}^{3}\right)$. When the tube was inserted into grain, its volume could be slightly less due to compression forces on the plastic tube, which can deform slightly when it is subjected to pressure from the grain.

When the mannequin was buried to its underarms with the tube inserted, the volume occupied by the grain within the tube changed by $0.03 \mathrm{~m}^{3}\left(2 \mathrm{ft}^{3}\right.$, or about 1.6 bushels based on $\left.1.25 \mathrm{ft}^{3} \mathrm{bu}^{-1}\right)$. When the mannequin was buried to its waist with the tube inserted, the volume of grain within the tube changed by $0.0249 \mathrm{~m}^{3}\left(0.88 \mathrm{ft}^{3}\right.$ or 0.7 bushels $)$. This was determined by first driving the tube to the specified depth and then quantifying the difference between the levels of corn inside the tube and outside the tube. The bulk density of the corn used for the insertion experiments was measured as $730 \mathrm{~kg} \mathrm{~m}^{-3}$ $\left(56.7 \mathrm{lb} \mathrm{bu}^{-1}\right)$. Assuming that no corn exited the area within the tube during insertion, the bulk density of the corn must have increased.

In the tests in which the mannequin was buried to its underarms and the tube was inserted from $15 \mathrm{~cm}$ (6 in.) below the underarms to just below the knees, the volume of the mannequin was calculated to be $0.074 \mathrm{~m}^{3}\left(2.6 \mathrm{ft}^{3}\right)$. The volume of the tube occupied by corn after the tube had been inserted, and the grain was assumed to have consolidated, was calculated as $0.3426 \mathrm{~m}^{3}\left(12.1 \mathrm{ft}^{3}\right.$ or 9.7 bushels). When the mannequin was buried to its waist with the tube inserted, the volume of the mannequin was $0.0509 \mathrm{~m}^{3}\left(1.8 \mathrm{ft}^{3}\right)$, and the volume of corn after the assumed consolidation was $0.3313 \mathrm{~m}^{3}\left(11.7 \mathrm{ft}^{3}\right.$ or 9.4 bushels).

When the mannequin was buried to its underarms, the volume of corn decreased by $0.0564 \mathrm{~m}^{3}$ (1.6 bushels). Assuming consolidation, the bulk density within the tube would theoretically have increased by $121 \mathrm{~kg} \mathrm{~m}^{-3}\left(9.4 \mathrm{lb} \mathrm{bu}^{-1}\right)$ based on the $56.7 \mathrm{lb} \mathrm{bu}^{-1}$ test weight. We assume that inserting the tube around the mannequin buried to its underarms increased the bulk density of the corn by $16 \%$ to $851 \mathrm{~kg} \mathrm{~m}^{-3}\left(66 \mathrm{lb} \mathrm{bu}^{-1}\right)$. When the mannequin was buried to its waist, the volume of corn decreased by $0.02467 \mathrm{~m}^{3}(0.7$ bushel $)$ and its bulk density would have increased by $54 \mathrm{~kg} \mathrm{~m}^{-3}\left(4.2 \mathrm{lb} \mathrm{bu}^{-1}\right)$. This would have increased the corn's bulk density by $9 \%$ to $798 \mathrm{~kg} \mathrm{~m}^{-3}\left(62 \mathrm{lb} \mathrm{bu}^{-1}\right)$.

Table 1 summarizes the percentage increases in the amount of pull force due to tube insertion and in the bulk density of the corn due to consolidation for the two scenarios. While the increases in bulk density (as a result of tube insertion) could account for the increases in pull force, it is interesting to note that the difference between the pull forces with and without the tube was greater in the waist scenario (26\%) than in the underarms scenario (22\%), although the calculated increase in bulk density due to consolidation was greater for the underarms scenario.

\section{Discussion}

An interesting observation made during testing had to do with the level of the grain within the rescue tube. After the tube was inserted around the mannequin, the level of the 
grain within the tube was less than the level outside the tube. This difference was $15 \mathrm{~cm}$ (6 in.) for the tests when the mannequin was entrapped to its underarms and the tube was driven into the grain so that the top of the tube was level with the mannequin's head. The difference was $8 \mathrm{~cm}$ ( 3 in.) when the mannequin was buried to its waist and the tube was

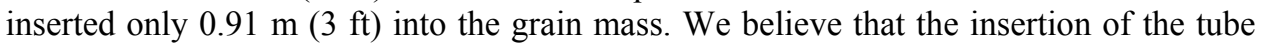
consolidated the grain and increased its bulk density. When the mannequin was buried to its waist, the bulk density increased by $54 \mathrm{~kg} \mathrm{~m}^{-3}\left(4.2 \mathrm{lb} \mathrm{bu}^{-1}\right)$ or $9 \%$. When the mannequin was buried to its underarms, the increase was $121 \mathrm{~kg} \mathrm{~m}^{-3}\left(9.4 \mathrm{lb} \mathrm{bu}^{-1}\right)$ or $16 \%$. This grain consolidation is supported by information found in the soil mechanics literature, where it is observed that there is a tendency for "densification" of the surrounding soil when driving a pile into a cohesionless soil (Horvath et al., 1996). The densification could be even greater if a human victim were involved instead of the mannequin due to the victim's efforts to self-extricate.

An increase in bulk density of the grain can explain the increase in the force needed to extricate the mannequin when the tube surrounded the mannequin compared to when no tube was present. Roberts et al. (2012) reported that the force required to insert the tube also increased. The increased force can be explained by observations of Horvath et al. (1996), who studied the force required to pull a $10 \mathrm{~mm}$ diameter glass rod from quartz sand contained within a quartz glass tube with an inner diameter of $51.5 \mathrm{~mm}$. Horvath et al. (1996) stated that "a linear increase of the [quartz] grain density yields an exponentially increasing friction force." We believe that the increase in bulk density caused a corresponding increase in friction between the shelled corn and the mannequin and between the corn and the tube walls, which increased the force needed to pull the mannequin from the corn when the rescue tube was used.

When the rescue tube was used with the mannequin entrapped to its waist, it was relatively easy to insert the tube into the grain mass. Only a little effort was required to drive

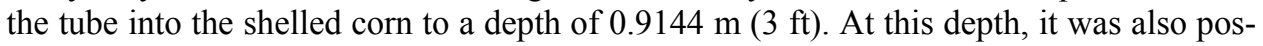
sible to pull the tube out of the grain manually.

When the mannequin was entrapped to its underarms, inserting the tube to the prede-

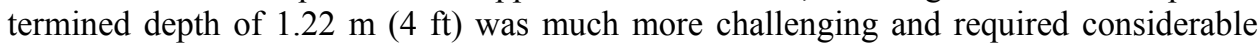
effort. Retrieving the tube from that depth was also very difficult. The winch had to be used to remove each tube panel individually because it could not be done manually. After the tube was winched out of the grain several times, its connecting joints separated from the panels, rendering the tube unusable. Additionally, the original drivers that came with the tube did not hold up under repeated insertion of the panels into the grain to a depth of

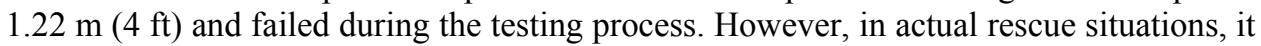
is unlikely that the drivers would be used to drive panels into grain with the frequency required in this research. As a result of these problems, the grain rescue tube manufacturer redesigned the driver and provided more specific instructions on the insertion procedure and recommended insertion depths.

\section{Evaluation of Similar Studies}

A direct comparison between the data collected in this study and the data collected by Schwab et al. (1985), discussed earlier, is not possible due to the different experimental procedures used. Schwab et al. (1985) evaluated the force (in N) experienced by their mannequin during a continuous pull. The force recorded in this study was the peak pull force (in $\mathrm{kg}$ or $\mathrm{lb}$ ) observed the instant the mannequin began to move up and out of the 
grain mass. However, some general comparisons are possible since the test mannequins used in both studies were $75 \mathrm{~kg}(165 \mathrm{lb})$ and $1.83 \mathrm{~m}(6 \mathrm{ft})$ in height.

Schwab et al. (1985) used a potentiometer and therefore was able to record the speed and distance at which his simulated victim (mannequin or peg) was winched from the grain mass. He buried the simulated victim until the head of the mannequin or top of the

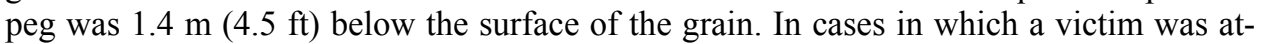
tached to a lifeline with a harness and subsequently fully engulfed, Schwab's findings regarding the forces required for extrication would be useful; however, this is rarely the case in actual entrapment incidents, where the victim is much more likely to be partially submerged in the grain. It is rare for a fully engulfed victim to survive. Once the mannequin or peg was buried, the winch was activated, and the mannequin or peg was pulled continuously until it was completely free of the grain. During the entire pulling process, the speed, depth, and pull were recorded, with the data expressed in N.

In this study, after the mannequin was buried, a small amount of slack was left on the winch cable so that the weight registering on the load cell was near zero. As noted previously, only the initial tug needed to get the mannequin moving up and out of the grain was recorded; the speed of pull was not recorded. Observation of the load cell readout revealed that the force quickly increased as the winch cable tightened. As the mannequin began to move, the readout began to decrease until the mannequin was completely out of the grain and the load cell displayed only the suspended weight of the mannequin and cable.

Schwab et al. (1985) did not specify points on the simulated victim's body at which the force was calculated. In this study, the waist of the mannequin was approximately

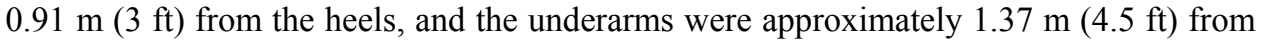
the heels. However, using the ten points of reference for grain depth that Schwab et al. (1985) established, the initial pull forces recorded by Schwab (1982) can be compared to those recorded in this study. These values are shown in table 2. Although the forces from this study are lower, the magnitudes are similar. The differences are reasonable, considering that the data from Schwab et al. (1985) were collected while the mannequin was in motion, whereas the data in this study were recorded at the moment the mannequin began to move up and out of the grain.

Based on the maximum pull force specified by OSHA Standard 1926.502(d)(16), discussed earlier, and the data collected in this study, it is theoretically possible to extricate a partially entrapped victim using the correct harness apparatus and appropriate mechanical assistance. The OSHA standard allows a maximum force on an employee, in a fall arrest situation, of $4003 \mathrm{~N}\left(900 \mathrm{lb}_{\mathrm{f}}\right)$ if using a body belt and $8007 \mathrm{~N}\left(1800 \mathrm{lb}_{\mathrm{f}}\right)$ if using a fullbody harness. None of the data from the vertical pull tests in this study or in the Schwab et al. (1985) study reached the magnitude of maximum acceptable load specified by the OSHA standard. However, we question whether it is valid to compare the forces on the body exerted by a fall arrest system with the forces placed on the body during extrication from grain. A major reason is that there have been documented cases in which injury was

Table 2. Average vertical pull force recorded at the waist and underarms in this study compared to the pound-force interpolated data from the Schwab et al. (1985) study.

\begin{tabular}{ccc} 
Reference & \multicolumn{2}{c}{ Vertical Pull Force, N $\left(\mathrm{lb}_{\mathrm{f}}\right)$} \\
\cline { 2 - 3 } Point & This Study & Schwab Study \\
\hline Waist & $1259(283)$ & $1321(297)$ \\
Underarms & $1766(397)$ & $2126(478)$ \\
\hline
\end{tabular}


inflicted on entrapment victims when attempts were made to physically pull them from the grain (Roberts et al., 2011). In addition, in most cases, first responders will not be aware of any physical conditions that may cause medical complications when the victim is exposed to high forces.

\section{Purdue University Agriculture Entrapment Database}

No cases were documented within the Purdue University Agriculture Entrapment Database (PUAED) in which an engulfed or deeply entrapped victim had successfully been pulled free from a grain mass without excessive harm being done to the victim. The PUAED contains several cases in which ropes were looped under the victim's armpits and then attached to powered lifting devices. In one instance, the victim had both arms dislocated; in another, the victim died as a result of his spine separating. An additional factor increasing the complexity of extrication of victims entrapped in grain bins or silos by means of an overhead or vertical pull is that many of these structures, especially those found on farms, do not have adequate overhead tie-off and anchor points, both of which are necessary for rope-rescue equipment. In one documented case, a farmer entered a bin using a harness and rope tied off to the top of the inside bin ladder. The victim was pulled into the flowing grain, and the forces were strong enough to pull the ladder free from the bin wall and bend it into the grain mass. The victim was found suffocated with both the harness and rope secured at both ends.

If a victim is entrapped without a body harness, the grain must first be cleared away from around the victim. This usually requires some form of a grain retaining wall or rescue tube. When enough grain has been removed to allow attachment of the harness, the victim can be completely freed by removing a relatively small amount of additional grain. Even if the victim is entrapped while wearing a body harness, there is still a significant risk of injury if a vertical pull is attempted, especially to the lower extremities and spine. For a safety harness to be effective, it must be worn snugly on the body. If not fitted or worn properly, the body harness can slide up the wearer's body to the point at which it is cutting into the legs, groin, stomach, and/or underarms.

\section{Conclusions}

This study sought to determine the amount of vertical pull required to extricate a simulated victim buried to its waist and underarms in a grain mass. Tests were conducted with and without the use of a grain rescue tube. The following are conclusions drawn from the study:

- Inserting the rescue tube around the simulated victim (mannequin) but not removing any grain from within the tube increases the amount of vertical pull needed for extrication. In the scenarios in which the victim was entrapped to the waist and to the underarms, placing the tube around the mannequin without removing grain increased the vertical pull by $26 \%$, i.e., from 1259 to $1584 \mathrm{~N}$ (283 to $356 \mathrm{lb}_{\mathrm{f}}$ ), and $22 \%$, i.e., from 1766 to $2153 \mathrm{~N}$ (397 to $484 \mathrm{lb}_{\mathrm{f}}$ ), respectively.

- Inserting the tube and then removing grain from the tube requires the least amount of vertical pull for extrication. In the test in which the mannequin was buried to its waist and grain was removed to its knees, the vertical pull decreased by $31 \%$, i.e., from 1584 to $1085 \mathrm{~N}$ (356 to $244 \mathrm{lb}_{\mathrm{f}}$ ). In the test in which the mannequin was buried to its underarms and grain was removed to waist level, the vertical pull de- 
creased by $38 \%$, i.e., from 2153 to $1330 \mathrm{~N}$ (484 to $299 \mathrm{lb}_{\mathrm{f}}$ ).

- Although direct comparison was not possible, the pull data from Schwab et al. 1985) appear to be similar to the data collected in this study.

- The pull forces recorded in this study are less than the maximum allowable force that employees are permitted to experience with fall-protection devices as specified by OSHA Standard 1926.502(d)(16).

- Based upon the forces measured in this study and findings from the previous studies reviewed, attempting to forcefully remove an entrapped victim, with or without a grain rescue tube, has the potential to result in severe injuries and possibly death.

\section{Recommendations}

The findings from this study should be made available to those engaged in the training of emergency first responders, who have a high probability of responding to grain entrapments and engulfments.

These findings should be incorporated into education and training resources that address potential hazards of grain entrapment and engulfment. Especially noteworthy is the finding that increased pull forces will be needed to extricate a victim from inside a grain rescue tube or comparable device if sufficient grain has not been removed from within the tube prior to extrication.

These findings should be included in the user instructions provided with grain rescue tubes and comparable devices. We recommend that the instructions include a warning not to attempt extrication of a victim inside the device without first removing grain to a level below the victim's waist.

Additional research is needed on the acceptable pull forces that can be absorbed by a body entrapped or engulfed in grain without causing serious injury during emergency extrication.

\section{References}

Horvath, V. K., Janosi, I. M., \& Vella, P. J. (1996). Anomalous density dependence of static friction in sand. Physical Rev. E, 54(2), 2005-2009. http://dx.doi.org/10.1103/PhysRevE.54.2005.

OSHA. (2008). Fall protection systems criteria and practices. OSHA Publ. No. 1926.502.

Washington, D.C.: Occupational Safety and Health Administration.

Roberts, M. J., Deboy, G. R., Field, W. E., \& Maier, D. E. (2011). Summary of prior grain entrapment rescue strategies. J. Agric. Safety Health, 17(4), 303-325. http://dx.doi.org/10.13031/2013.39804.

Roberts, M. J., Field, W. E., Maier, D. E., \& Stroshine, R. L. (2012). Determination of effort required to insert a rescue tube into various grain types. J. Agric. Safety and Health, 18(4), 293-308. http://dx.doi.org/10.13031/2013.42331.

Schmechta, V. H., \& Matz, A. (1971). Zum versinken in Getreide [About engulfment in grain]. Zeitschrift fuer die Gesamte Hygiene und ihre Grenzgebiete, 17(8), 565-567.

Schwab, C. V. (1982). Inflow velocity and forces acting on a person trapped in enveloping flow of granular materials. MS thesis. Lexington, Ky.: University of Kentucky.

Schwab, C. V., Ross, I. J., Piercy, L. R., \& McKenzie, B. A. (1985). Vertical pull and immersion velocity of mannequins trapped in enveloping grain flow. Trans. ASAE, 28(6), 1997-2002. http://dx.doi.org/10.13031/2013.32555. 